\title{
Compressive Strength of Cement Mortar Containing Carbon Nanotubes (CNTs) under Sulfate Attack and Dry-Wet Cycling Environment
}

\author{
Weiwen $\mathrm{LI}^{1}$, Yaru JIA ${ }^{2}$, Ruoxu $\mathrm{SHEN}^{3}$, Feng XING ${ }^{4}$, Jing ZHENG* \\ School of Civil Engineering \\ Key Laboratory of Durability for Marine Civil Engineering, Shenzhen University \\ Shenzhen, China. \\ E-mail: liweiwen@szu.edu.cn, jiayaruanan@163.com, ruoxushen@gmail.com, xingf@szu.edu.cn,*1246855296@qq.com
}

\begin{abstract}
The compressive strength and hydration process of cement-based materials containing with carbon nanotubes (CNTs) were investigated in this paper. The experimental results showed that the compressive strength of QC-CNT group under standard curing and dry-wet cycles was higher than that of Control group under different testing ages; The compressive strength under the standard curing was higher than that of the same group under dry-wet cycles; With the increasing of dry-wet cycling age, the compressive strength of Control group and QC-CNT group decreased gradually. Hydration exothermic curve in $72 \mathrm{~h}$ showed the same trend in Control group and QC-CNT group. Exothermic peaks appear basically the same period .The peak value and the hydration reaction rates in each stage of the $\mathrm{QC}$-CNT group were always higher than those in the Control group. The experimental results show that $\mathrm{CNT}$ can significantly improve the sulfate resistance of cement-based materials in two aspects: preventing harmful ions from entering the material and preventing cracking.
\end{abstract}

Keywords-carbon nanotube, compressive strength, cement hydration heat, wet-dry cycle, sulfate erosion

\section{INTRODUCTION}

Sulphate attack is one of the key issues of durability for cement-based materials [1].Cement-based materials as an alkaline material is susceptible to damage in the sulfate environment. Sulfate atttack from the reaction mechanism is caused by chemical reaction of concrete degradation, and it is considered to cause deterioration of concrete damage as one of the main reasons.

The essence of sulfate ions destroying the concrete is that the external sulfate ion infiltrates into the gaps and pores of the concrete and chemically reacts with the hydration products of cement to generate swelling erosive products with minimal solubility. There are Gypsum-type expanded destruction and ettringite-type expanded destruction. Erosion of ettringite-type sulfate is belonging to the typical sulfate attack. Sulfate ions enter into the cement matrix and react with calcium hydroxide to form calcium sulfate. Calcium sulfate then acts on the hydrated calcium aluminate to form trisulfide hydrated sulphoaluminate (ettringite crystals)[2]. When sulfate ions in the etching solution reach a certain concentration, or sulfate ions concentration in the materials increases due to the wet-dry cycle, not only the ettringite crystallization will be produced but also the gypsum crystal will be precipitated. El-Hachem et al.[3]reported that the expansion rate of cementitious materials exposed to sulphate increases with the $\mathrm{C} 3 \mathrm{~A}$ content in the cement. As the volume of both crystals increase, the expansion stress eventually exceeds the ultimate tensile stress of the concrete, causing cracking, spalling and destruction of the concrete. In the drywet cycling environment, this action happens frequently, causing the internal expansion of the structure, which leads to the peeling between the material layers, which seriously affects the structural safety [4].

Dry-wet cycle is considered to be a worst environmental condition that affects the durability of concrete. Concrete can easily lose its bearing capacity and reduce its durability under the dry-wet cycling environment. Under complete immersion conditions, the concrete is in a state of approximate water saturation without head pressure and the solution flow rate is zero. The effect of capillary siphon pressure on water flow is equivalent to the effect of water saturated concrete subjected to $214 \mathrm{MPa}$ head pressure [5]. Therefore, the alternating wet and dry environment will accelerate the migration of sulfate inside the structure.

When the concrete is in a sulphate environment, sulfate and water enter the interior of the concrete together and chemically react with the substrate. When the concrete is in a dry condition, the internal moisture will be completely evaporated, leaving the sulphate inside the concrete. As the concrete returns to the sulphate environment, sulphate reenters the concrete and becomes saturated. When it enters the dry state, the water evaporates again and the sulfate enters the interior of the concrete because of the concentration difference existing inside and outside the concrete. This alternating wet and dry erosion process occurs repeatedly, exacerbating the erosion process of concrete sulfate, salt content of concrete continued to increase. Through experiments, Robert et al. [6] compared the volume expansion of concrete after soaking in sodium sulfate solution, the wet-dry circulation of sodium sulfate solution and the freeze-thaw cycle of sodium sulfate solution. The experiments showed that the volume expansion was the largest in the wet-dry cycle and that in the freeze-thaw cycle was the middle, in continuous immersion was the smallest, indicating that the wet-dry cycle has a very serious impact on the durability of the material.it was also observed through experiments that the mortars subjected to wet-dry cycles of sulphate attack were more severely damaged than ones immersed in a sulphate solution [7].

As carbon nanotubes can make the composite microstructure more dense, reducing the production of 
harmful pores can reduce the invasion of harmful ions with the potential to improve the durability of the material.

Some researchers have found that CNT is helpful for improvement of durability. Han et al. [8] found that multiwalled CNT (MWCNT) could decrease the absorption coefficient, water permeability and gas permeability of cement-based materials; Weiwen Li et al. [9] found that with addition of carbon nanotube to the cement mortar, pores with a diameter of bigger than $200 \mathrm{~nm}$ are likely to be refined to 50-100 nm; the disconnection of pores was also improved. However, CNT was also reported to have detrimental effects on durability. Del et al. [10] detected a slight increase in porosity when CNT was added to cement-based material; the results also showed that the addition of CNT increased the degradation of concrete under carbonation and promoted the ingress of chloride ions.

In practical structural engineering, cement materials are often attacked both dry-wet circulation and salt erosion, so carbon nanotubes-cement mortar has more extensive application in sulfate resistance. Based on the above understanding,in the paper, the wet-dry cycle method is used to study the capability of anti-sulphate attack of carbon nanotubes-cement mortar, and the related theoretical analysis is carried out.

\section{EXPERIMENTAL DESIGN}

The carbon nanotubes-cement mortar prepared by adding CNTs in an amount of $0.0 \%$ and $0.3 \%$ was set as the control group and the QC-CNT group, respectively. The specimens for two experimental groups were respectively made according to the different mixing ratios shown in Table 1 .

Standard sand and cement are mixed together with the ball mill mixture prepared in the previous section in a mixing pan. The production process requires $\mathrm{JJ}-5$ cement mortar mixer slowly stirred for 2 minutes, then add water and superplasticizer for rapid mixing for 1 minute. After the end of the well-mixed cement mortar into standard mould (160 $\mathrm{mm} \times 40 \mathrm{~mm} \times 40 \mathrm{~mm}$ ), and then the mould is placed on a vibrating table to be shaked.The specimens were demoulded after 24 hours of curing under the standard curing conditions of $20 \pm 2{ }^{\circ} \mathrm{C}$ and humidity of $90 \%$. The samples were placed in standard curing rooms and maintained until the 28 days.
The compressive strength and corrosion resistance coefficient is used to characterize the destructive effect of the dry-wet cycle on the concrete. The sulfate resistance test of the cement mortar is carried out according to GB/T500822009. For the experiment, The oven are set in the constant temperature as $(80 \pm 5){ }^{\circ} \mathrm{C}$, and infusion tank with $8 \%$ $\mathrm{Na} 2 \mathrm{SO} 4$ solution is equipped with sodium sulfate, in which the testing solution should be replaced per month. The experimental ages are set at 30d, 60d and 90d, respectively. After the curing process is done, the specimens will be put into the oven with $80^{\circ} \mathrm{C}$ for $48 \mathrm{~h}$. After drying and cooling, the specimen is placed in a sulfate immersion tank, soaked in a sulfate solution at $25^{\circ} \mathrm{C}$ for 8 hours. The specimen was taken out and air-dried, then baked in a drying oven at $80^{\circ} \mathrm{C}$ for 16 hours.

Experiments ensure the dry-wet cycling test per day, the dry-wet cycling test were set at 30,60 and 90 times. The specimens were taken from the oven every $30 \mathrm{~d}$ period and tested for compressive strength along with specimens under standard curing. From the Equation (1) to obtain the corresponding compressive strength corrosion coefficient $\mathrm{Kf}$.

$$
K_{f}=\frac{f_{c n}}{f_{c 0}} \times 100
$$

where,

$\mathrm{K}_{f}$-- the corrosion resistance coefficient of compressive strength $(\%)$;

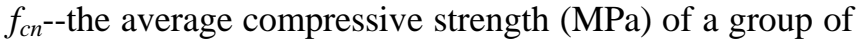
specimens corroded by sulfate after $\mathrm{N}$ cycles;

$f_{c 0}$ - the average compressive strength $(\mathrm{MPa})$ for a control group.

Cement hydration heat test were carried out for both the control and QC-CNT group, the sample of the control group was $10 \mathrm{~g}$ of ordinary unhydrated cement, and $10 \mathrm{~g}$ of a mixture of ordinary unhydrated cement and carbon nanotubes was used as a sample of the QC-CNT group. Each sample was hydrated with $4.5 \mathrm{~g}$ deionized water. The exothermic rate of $72 \mathrm{~h}$ hydration reaction and the total amount of hydration heat were recorded by the instrument Germany TONI7388, and the corresponding curves were obtained.

TABLE I. THE MIXING RATIO OF CARBON NANOTUBES-CEMENT MORTAR (SET THE CEMENT MASS OF 100G) UNIT: G

\begin{tabular}{cccccc}
\hline Group & Cement & Sand & Water & CNT & Superplasticizer \\
\hline Control & 100 & 100 & 45 & 0 & 0.2 \\
QC-CNT & 100 & 100 & 45 & 0.3 & 0.4 \\
\hline
\end{tabular}


TABLE II. COMPARISON OF COMPRESSIVE STRENGTH OF CARBON NANOTUBES CEMENT MORTAR AND ORDINARY MORTAR UNDER SULFATE ATTACK AT DIFFERENT AGES

\begin{tabular}{|c|c|c|c|c|c|c|}
\hline \multirow{2}{*}{ Group } & \multicolumn{6}{|c|}{ Compressive Strength(MPa) } \\
\hline & Age & S1 & S2 & $\mathbf{S 3}$ & Average & $K_{f}(\%)$ \\
\hline \multirow{4}{*}{ Control } & Od & 48.63 & 47.25 & 49.75 & 48.54 & - \\
\hline & $30 \mathrm{~d}$ & 53.72 & 52.96 & 53.28 & 53.32 & - \\
\hline & $60 \mathrm{~d}$ & 49.15 & 48.35 & 47.14 & 48.21 & - \\
\hline & $90 \mathrm{~d}$ & 27.50 & 28.75 & 33.13 & 29.79 & - \\
\hline \multirow{4}{*}{ QC-CNT } & Od & 51.38 & 51.81 & 53.44 & 52.21 & - \\
\hline & $30 \mathrm{~d}$ & 48.90 & 48.12 & 47.75 & 48.26 & - \\
\hline & $60 \mathrm{~d}$ & 52.45 & 50.10 & 50.51 & 51.02 & - \\
\hline & $90 \mathrm{~d}$ & 30.50 & 36.50 & 27.13 & 31.38 & - \\
\hline \multirow{5}{*}{ Control(D-W) } & Od & 48.63 & 47.25 & 49.75 & 48.54 & $100 \%$ \\
\hline & $30 \mathrm{~d}$ & 42.71 & 45.23 & & 44.87 & $93.0 \%$ \\
\hline & & & & $\begin{array}{l}46.66 \\
41.65\end{array}$ & & \\
\hline & $60 \mathrm{~d}$ & 45.73 & 41.11 & & 42.83 & $88.8 \%$ \\
\hline & $90 \mathrm{~d}$ & 40.44 & 40.40 & 40.60 & 40.48 & $84.9 \%$ \\
\hline \multirow{4}{*}{ QC-CNT(D-W) } & Od & 51.38 & 51.81 & 53.44 & 52.21 & $100 \%$ \\
\hline & $30 \mathrm{~d}$ & 30.50 & 36.50 & 27.13 & 31.38 & $95.2 \%$ \\
\hline & $60 \mathrm{~d}$ & 40.44 & 40.40 & 40.60 & 40.48 & $93.9 \%$ \\
\hline & $90 \mathrm{~d}$ & 46.93 & 40.30 & 49.20 & 45.48 & $90.6 \%$ \\
\hline
\end{tabular}

( $\mathrm{K}_{f-}$--the corrosion resistance coefficient of compressive strength.)

\section{RESULTS AND ANALYSIS}

Fig. 1 and Fig. 2 showed that the compressive strength of QC-CNT group under both standard curing and dry-wet cycling was higher than that of control group while the compressive strength of QC-CNT group and control group under standard curing are higher than those of the same group under the dry-wet cycling condition. With the increasing of testing age, the compressive strength of Control and QC-CNT under the standard curing basically remained unchanged, and the compressive strength of Control and QCCNT under the dry-wet cycles gradually decreased. The corrosion resistance coefficients of compressive strength of ordinary cement mortar were $93.0 \%, 88.8 \%$ and $84.9 \%$ at the age of $30 \mathrm{~d}, 60 \mathrm{~d}$ and $90 \mathrm{~d}$, respectively. The corrosion resistance coefficient of compressive strength of CNTs with the content of $0.3 \%$ is $95.2 \%, 93.9 \%$ and $90.6 \%$ respectively. As shown in Fig. 3, The results of hydration exothermic curve in $72 \mathrm{~h}$ show that the hydration exothermic rate curve of Control and QC-CNT at each stage is consistent and the two exothermic peaks appear basically the same. The peak of QC-CNT was higher than that of Control group, and the hydration reaction rate of each stage was also higher than that of Control group. It shows that carbon nanotubes can accelerate the hydration heat rate of cement-based materials, accelerate the early hydration process of cement and promote 
the early hydration degree. Thus, CNT can improve the interior microstructures of the cement matrix.

Sulfate erosion is mainly caused by the repeated process of harmful ions entering into the interior, reaction producing crystals and crystal expansion and destruction. Strengthening the microstructure of cement-based materials and reducing the formation of harmful pores is the most fundamental way to prevent harmful ions from entering into the interior. As carbon nanotubes can improve the porosity of cement mortar, the microstructure of the cement mortar is improved.
When the crystal volume is expanded, there is an internal concentration stress. Because of its strong mechanical properties and high toughness, carbon nanotubes have the ability to bridge the hydration products, thus improving the mechanical properties of composite; carbon nanotubes dispersed by ball milling in the cement matrix improved mechanical strength of the carbon nanotube / cement compositeto resist matrix cracking caused by internal expansion pressure [9].

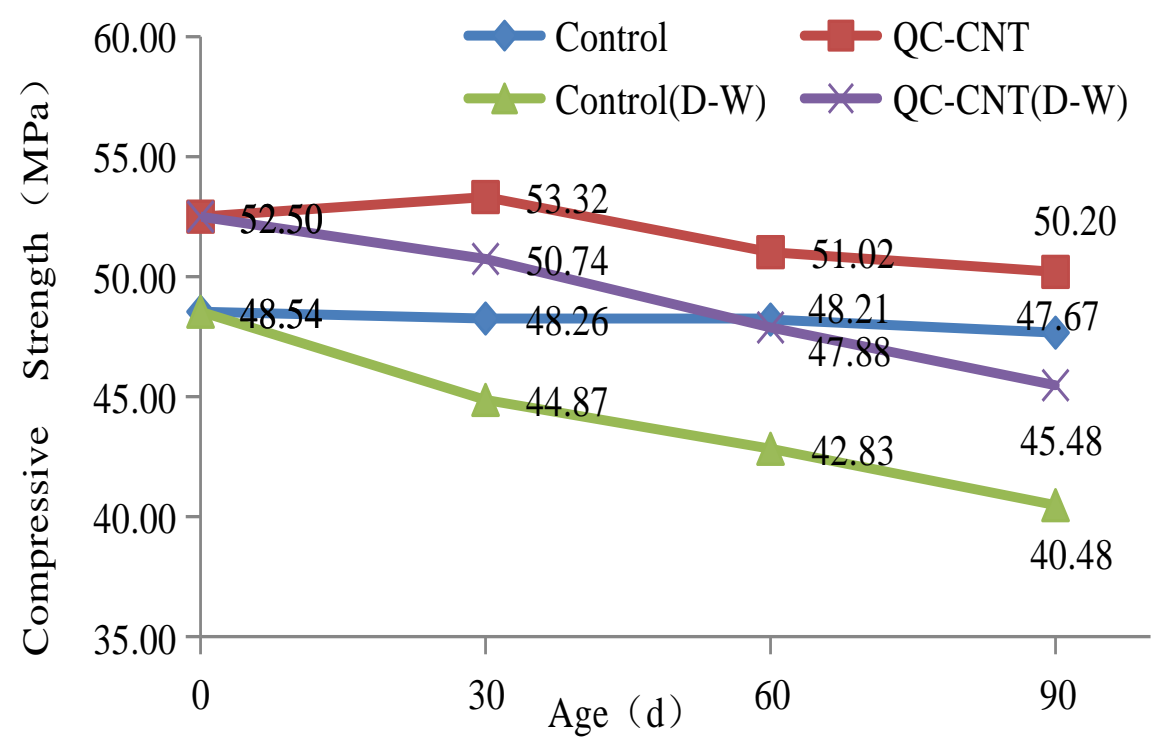

Figure 1. Comparison of strength between carbon nanotubes cement mortar and ordinary mortar under sulfate erosion at different ages(MPa).

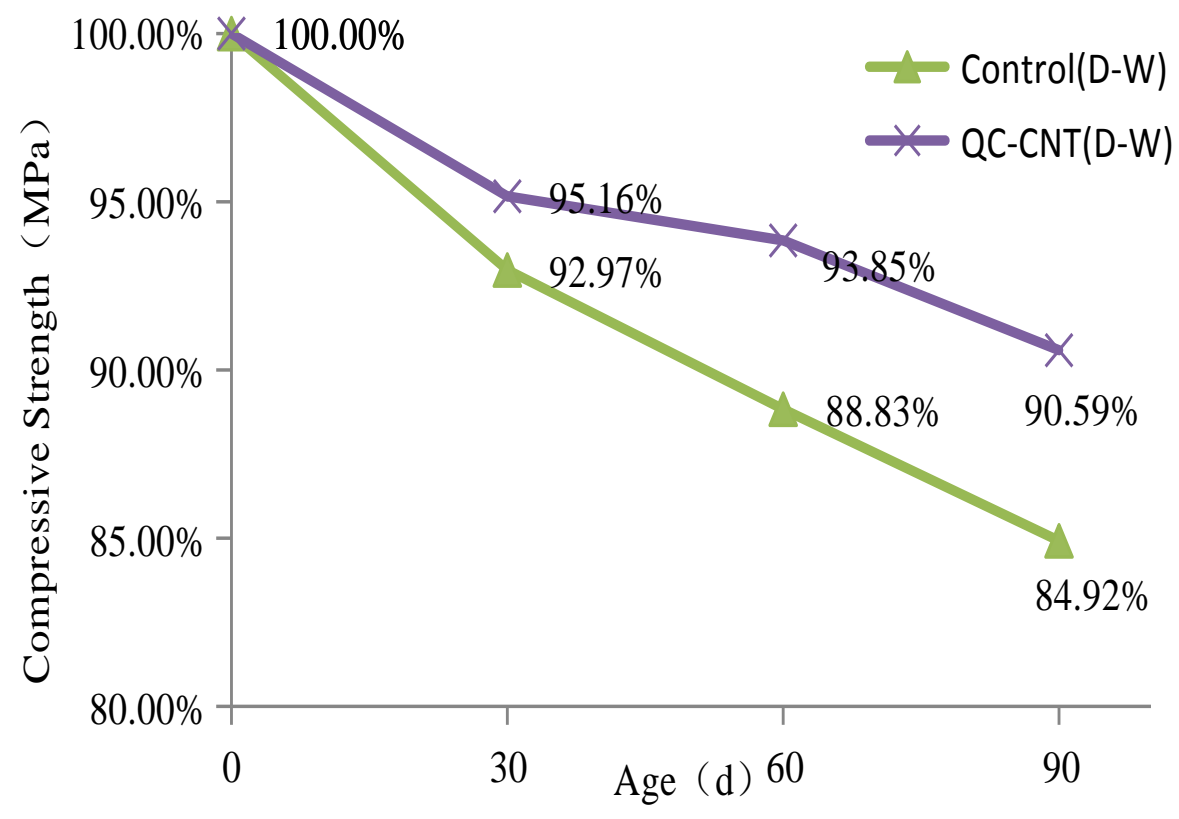

Figure 2. Corrosion resistance coefficients of compressive stresses under sulfate erosion at different ages. 


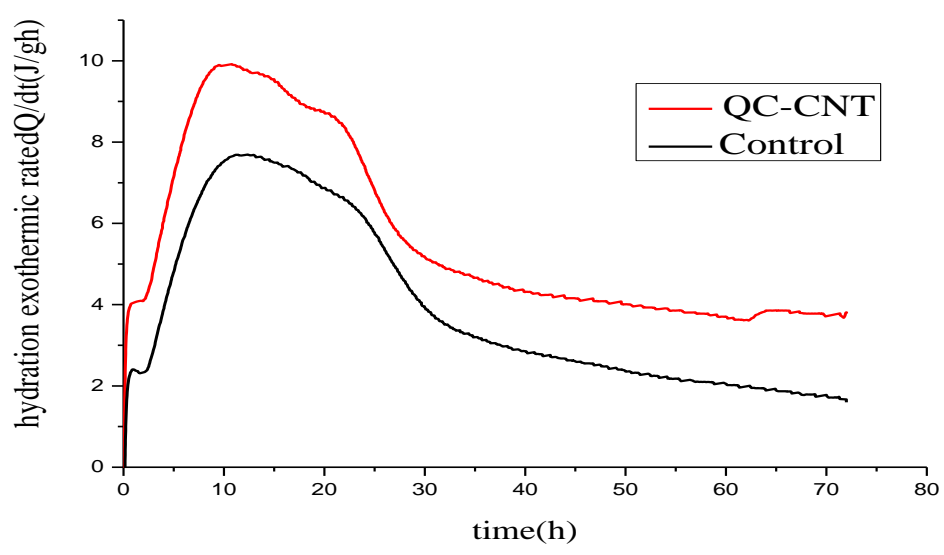

Figure 3. Hydration exothermic rate curve of carbon nanotube cement paste and ordinary cement paste.

\section{CONCLUSIONS}

This article describes the effect of sulphate attack on cement mortar incorporated with carbon nanotubes under dry-wet cycles. The study used two different concentrations of carbon nanotubes $(0 \%, 0.3 \%)$ cement mortar. The effect of carbon nanotubes on the compressive strength and hydration process of cement paste was studied. Available from the study:

- Carbon nanotubes help to accelerate early hydration and enhance the internal density of the matrix.

- Carbon nanotubes can significantly improve the sulfate resistance of cement mortars in terms of preventing harmful ions from entering the interior of the material and preventing matrix cracking.

\section{ACKNOWLEDGMENTS}

The authors would like to gratefully acknowledge Guangdong province science and technology plan projects (Project No. 2015A010105029) and the Shenzhen Strategic Emerging Industry Development Special Fund (No. JCYJ20150625102603853) for financial support on this study.

\section{REFERENCES}

[1] C. Ahmet and Y.Sükrü:'Investigation of mechanical and mineralogical
[2] Makar J M, Chan G W. Growth of Cement Hydration Products on Single-Walled Carbon Nanotubes[J]. Journal of the American Ceramic Society, 2009,92(6):1303-1310.

[3] R. El-Hachem, E. Rozière, F. Grondin, and A. Loukili: 'Multi-criteria analysis of the mechanism of degradation of Portland cement based mortars exposed to external sulphate attack', Cem. Concr.Res., 2012, 42, 1327-1335.

[4] Song H, Lee C, Ann K Y. Factors influencing chloride transport in concrete structures exposed to marine environments[J]. Cement and Concrete Research, 2008,30(2):113-121.

[5] Mindess S, Young J F, Darwin D1 Concrete (2nd ed1 Pearson Education) [M]1 .Chemical Industry Press,20041.

[6] Polder R B, Peelen W H A. Characterisation of chloride transport and reinforcement corrosion in concrete under cyclic wetting and drying by electrical resistivity[J]. Cement and Concrete Composites, 2002,24 (5): 427-435.

[7] Y. D. Liao, Y. C. Yang, C. H. Jiang, X. G. Feng \& D. Chen (2015).Degradation of mechanical properties of cementitious materials exposed to wet-dry cycles of sulphate solution, Materials Research Innovations, 19:sup5, S5-173-S5-177.

[8] Han, B.; Yang, Z.; Shi, X.; Yu, X. Transport properties of carbonnanotube/cement composites. J. Mater.Eng. Perform. 2013, 22, 184 189.

[9] Weiwen Li, Weiming Ji. Investigation on the Mechanical Properties of a Cement-Based Material Containing Carbon Nanotube under Drying and Freeze-Thaw Conditions[J]. materials,2015,14 (12): 8780-8792.

[10] Del, C.C.M.; Galao, O.; Baeza, F.J.; Zornoza, E.; Garcés, P. Mechanical properties and durability of CNT cement composites. Materials 2014, 7, 1640-1651. 